\title{
LAS MODULACIONES ANTIPOÉTICAS EN TRES POETAS COLOMBIANOS: ÓSCAR HERNÁNDEZ, JAIME JARAMILLO PANESSO Y ANÍBAL ARIAS
}

\author{
Guillermo Molina Morales \\ Instituto Caro y Cuervo (Colombia) \\ guillermo.molina@caroycuervo.gov.co
}

Recibido: 16/05/2020 - Aprobado: 02/07/2020 - Publicado: 15/04/2021

DOI: doi.org/10.17533/udea.lyl.n79a24

Resumen: Este artículo estudia los trabajos de Óscar Hernández (1925-2017), Jaime Jaramillo Panesso (1938) y Aníbal Arias (1948). En Las contadas palabras, Hernández utiliza elementos antipoéticos para desarrollar una retórica populista que mantiene la elevación del poeta. En Antipoemas de un malevo, Jaramillo Panesso se sumerge en ambientes urbanos y marginales con vocación documental y algunos logros basados en la ambivalencia. En Motivos ajenos a la voluntad, Arias transmite la violencia en la propia forma poética mediante fragmentos broncos que aparentan poca elaboración literaria. En conjunto, estas obras generan un cambio en la línea antipoética de la literatura colombiana.

Palabras clave: Óscar Hernández; Jaime Jaramillo Panesso; Aníbal Arias; poesía colombiana; antipoesía.

\section{THE ANTIPOETIC MODULATIONS IN THREE COLOMBIAN POETS: ÓSCAR HERNÁNDEZ, JAIME JARAMILLO PANESSO, AND ANÍBAL ARIAS}

\begin{abstract}
This article studies the works of Óscar Hernández (1925-2017), Jaime Jaramillo Panesso (1938), and Aníbal Arias (1948). In Las contadas palabras, Hernández uses antipoetic elements to develop a populist rhetoric that maintains the poet's elevation. In Antipoemas de un malevo, Jaramillo Panesso immerses himself in urban and marginal environments with a documentarian vocation and some achievements based on ambivalence. In Motivos ajenos a la voluntad, Arias transmits violence in the poetic form itself, through gruff fragments that appear to have little literary elaboration. As a whole, these works make a change in the antipoetic line of Colombian literature.
\end{abstract}

Key words: Óscar Hernández; Jaime Jaramillo Panesso; Aníbal Arias; Colombian poetry; antipoetry. 


\section{Introducción}

$\mathrm{E}$

1 presente artículo inicia con una premisa: los poetas colombianos del siglo xx que escriben en español forman parte de las corrientes generales de la poesía moderna occidental. Como es natural, cada poeta desarrolla diferentes problemáticas y modos expresivos, y también puede compartir preocupaciones con otros poetas de la misma nacionalidad o generación, pero este hecho no debe hacer olvidar al lector el marco común de las diversas exploraciones. De esta manera, se evita la cortedad de miras sobre la que advierte Hugo Friedrich (1959):

La crítica de la lírica contemporánea comete casi siempre el error de tomar únicamente en consideración un país determinado y los veinte o treinta últimos años. La consecuencia de ello es que una poesía toma el aspecto de un «cambio» radical, y que, entre la lírica de 1945 y la de 1955, se admiran diferencias que ni siquiera equivalen a la que puede existir entre dos distintos seguidores de unos mismos modelos (pp. 7-8).

En efecto, muchas veces la poesía colombiana se ha estudiado de forma aislada, como si la modernidad comenzara con José Asunción Silva, la vanguardia fuera un invento de Luis Vidales y la poesía urbana una creación de Mario Rivero. Este enfoque tiene el problema adicional de resultar una profecía autocumplida: los jóvenes poetas se insertan en un panorama estrictamente local y olvidan las posibilidades de una tradición compartida.

El origen de esta gran tradición, la de la poesía moderna occidental, suele situarse en Charles Baudelaire. Aunque pueden encontrarse síntomas de la ruptura desde comienzos del siglo XIX — por ejemplo, en las Baladas líricas de Coleridge y Wordsworth—, la importancia de Las flores del mal es indudable. Walter Benjamin (1999) resumió el valor del poeta parisino con una frase: «ha colocado la experiencia del shock en el centro de su tarea artística» (p. 23). Esta observación, como explica el propio crítico, se debe interpretar de dos maneras. Por un lado, Baudelaire reflejó en su poesía el shock de la cosmovisión moderna, es decir, la ruptura con la metafísica. Por otro lado, esta visión del mundo, junto con su correspondiente expresión poética — que lleva, por ejemplo, a descreer en las formas tradicionales - , genera un shock en el lector. El efecto, en cuantiosas ocasiones, es buscado por los propios poetas, en lo que Octavio Paz denominó «tradición de la ruptura». Se podría decir que toda la poesía moderna nace de este shock, de esta grieta.

A partir de Baudelaire, uno de los principales teóricos de la modernidad poética, el ya citado Hugo Friedrich (1959), reconoció dos vías principales de exploración.

Se trata de las mismas que en el siglo pasado iniciaron Rimbaud y Mallarmé. En resumen y para entendernos diremos que la primera es una lírica formalmente libre y alógica, y la segunda una lírica intelectual y de formas rigurosas (p. 225).

En efecto, tanto el desarreglo de los sentidos de Rimbaud como el intento de abolir el azar de Mallarmé - es decir, de reconectar con el absoluto perdido - han generado dos caminos muy transitados por los poetas modernos.

Ahora bien, estas dos opciones forman parte de una misma línea de trabajo basada en la interiorización del poeta, lo que lleva a la progresiva separación del artista y los lectores, sobre la que Friedrich hizo gran énfasis. 
Las modulaciones antipoéticas en tres poetas colombianos: Óscar Hernández, Jaime Jaramillo Panesso y Aníbal Arias

Sin embargo, es necesario tener en cuenta otra línea igualmente significativa, que Hamburger (1991) denominó «antipoética»: «... una forma exagerada del bajo mimetismo, austeramente dedicado a expresar las cosas tal como son, en el lenguaje de la gente tal como lo habla» (p. 269). De esta manera, se llega a una dicotomía interior/exterior que, por seguir ahora la tradición anglosajona, se puede ejemplificar mediante la oposición del I'm nobody! Who are you? de Dickinson y el «...yo soy el hijo de Manhattan» de Whitman. Es decir, entre quienes exploran los límites del lenguaje para llegar a un más allá y quienes prefieren limitarse a la vida cotidiana.

Esta segunda línea ha mostrado una gran capacidad de renovación permanente mediante la inclusión de elementos provenientes de lo «bajo», de lo tradicionalmente excluido por la poesía o, en otras palabras, de lo antipoético. Es posible resumir estos elementos renovadores en tres grupos: los referentes materiales y cotidianos, con énfasis en la vida urbana; el lenguaje coloquial, con vocabulario y construcciones sintácticas que se acercan a los empleados en una conversación; y el tono humorístico, con el recurso especial de la ironía, como forma de evidenciar la falta de certidumbres metafísicas. Estos rasgos se materializan en la preferencia de la metonimia sobre la metáfora, es decir, en la selección de escenas y detalles significativos, a menudo presentados de forma narrativa, en lugar de la elevación de los referentes a un plano superior mediante el simbolismo.

Si por un momento se pone el enfoque en la poesía escrita en Colombia, pronto se evidencia que esta línea de trabajo ha sido minoritaria. Paradójicamente, esta misma marginalidad ha permitido que los «antipoetas» puedan adquirir una pátina de escándalo, como sucedió con los «nadaístas», que en realidad formaban un movimiento de retaguardia. Otros autores que presentan rasgos antipoéticos en el contexto nacional son el José Asunción Silva de las Gotas amargas, Luis Carlos López, León de Greiff y Luis Vidales, por citar solamente a los pioneros. En la época en que comenzaron a publicar los poetas que se estudian en este artículo, es muy celebrada la propuesta urbana de Mario Rivero y, a nivel continental, la antipoesía de Nicanor Parra ${ }^{1}$. Con todo, los tres poetas del corpus no han sido ubicados en generaciones, grupos o tendencias nacionales - en parte, por permanecer radicados fuera de la capital del país - , lo que facilita su estudio en el marco más amplio de la poesía occidental.

Una vez definida la línea antipoética — referentes cotidianos, lenguaje coloquial, tono irónico y tendencia a la metonimia_-, el objetivo del presente artículo es analizar las realizaciones concretas en tres libros de sendos autores: Óscar Hernández (1925-2017), Jaime Jaramillo Panesso (1938) y Aníbal Arias (1948). Se trata, por lo general, de poetas poco conocidos en el panorama nacional —y aún menos conocidos en el continental—, que han sido seleccionados por presentar variaciones significativas dentro de unas mismas coordenadas. No basta con situar a un poeta en una línea determinada, con similares elementos es posible construir propuestas estéticas muy distintas, y es deber del investigador atender a esta riqueza.

Antes de comenzar el análisis de cada poeta, conviene subrayar la necesidad de afinar la mirada crítica con este tipo de poesía, que suele parecer fácil. Gabriel Zaid (2012) afirmó que «hay una incomprensión desconcertante

1. La referencia a Nicanor Parra puede crear confusiones respecto al término «antipoesía». Es necesario aclarar que el presente artículo no toma el término según lo pensaba Parra y, con él, gran parte de la crítica hispana. í Se apuesta por una definición más amplia, no ligada a un autor — ni siquiera a una lengua_-, sino a una línea estética de la poesía moderna occidental. Como se ve anteriormente, se define esta línea en tres rasgos: referentes materiales y cotidianos, lenguaje coloquial y tono humorístico. La «antipoesía» de Parra, sin duda, forma parte de esta línea de trabajo, pero también lo hace la llamada «poesía coloquial» o «conversacional» que la crítica hispana ha diferenciado del modelo de Parra. 
Las modulaciones antipoéticas en tres poetas colombianos: Óscar Hernández, Jaime Jaramillo Panesso y Aníbal Arias hacia la poesía que sí se entiende [...]. [Los profesores] no entienden nada porque creen entender. Abandonan las cautelas más elementales» (p. 86). Como comenta Zaid a propósito de José Emilio Pacheco, el problema suele suceder con los críticos que minusvaloran esta poesía por considerarla superficial y homogénea. Esto también sucede, es preciso añadir, a la hora de dar elogios: se exalta la sencillez de las obras como un valor en sí mismo, y se evita pensar en las complejidades que subyacen a los poemas. Este estudio, además de rescatar la obra de los tres autores, pretende ahondar en las estrategias retóricas de la poesía «que sí se entiende» para mostrar algunas de las posibilidades que ofrece esta línea de trabajo.

\section{Una poesía populista: Las contadas palabras, de Óscar Hernández}

Óscar Hernández Monsalve (Medellín, 1925-2017) fue un conocido periodista y literato antioqueño, con numerosos libros publicados en los géneros de la novela, el cuento, la crónica y la poesía. En poesía, sus publicaciones se concentran en dos épocas distanciadas: entre los años 1950 y 1966 aparecen cinco obras — la segunda es la más conocida, Las contadas palabras, en la que se centra el análisis-, a las que sigue un silencio poético que se rompió solo hasta el siglo XXI. En los últimos años de su vida, Hernández publicó un amplio número de poemas, en libros exentos y en antologías, y también recibió varios homenajes, sobre todo en su Medellín natal.

En la bibliografía secundaria sobre la poesía de Hernández, no se encuentran monografías académicas, pero sí comentarios elogiosos procedentes de poetas de diversas generaciones, desde Fernando Charry Lara (19202004), Juan Manuel Roca (1946) y Santiago Mutis (1951) hasta Henry Alexander Gómez (1982) y Santiago Espinosa (1985). Todos ellos coinciden en destacar la humildad del poeta y de su propuesta estética, que consiste en el lenguaje sencillo, la mirada callejera y el tono despreocupado, a menudo irónico, que suele emplear en los versos. Estos rasgos ubican a Hernández en la línea antipoética de la cual se habló en la introducción. A juicio de los poetas/críticos que se han ocupado de su obra, su aparente sencillez otorga un valor especial a este poeta en el contexto de la solemne poesía colombiana.

Para dar un ejemplo es pertinente referirse a la lectura del poeta Juan Manuel Roca (2012), quien destacó en la poesía de Hernández los «vocablos humildes que desde su escritura nos cobijan y nos acompañan sin alardes» (p. 173). Ciertamente, los vocablos son humildes, ya que el poeta elige expresiones cercanas al habla coloquial. Sin embargo, lo que Roca n detectó es que Hernández utilizó estos vocablos como plataforma para el mayor de los alardes: el auto-ensalzamiento del poeta como oráculo. En este sentido, los poemas que se estudiarán en este artículo no «nos acompañan», como decía Roca, sino que imponen un camino a seguir.

Gran parte del éxito de Hernández — y de la incomprensión de sus lectores — se debe a las artes poéticas en verso que publicó. En estos poemas se halla una visión de la poesía que confirma los rasgos antipoéticos, pero que también, de forma implícita, los direcciona hacia un objetivo en cierta medida inesperado, que se puede llamar «populista». Este concepto, habitualmente asociado a la política, ha adquirido en los últimos años connotaciones negativas. En el presente estudio se limita a la definición estándar: intento de atraer el mayor número posible 
Las modulaciones antipoéticas en tres poetas colombianos: Óscar Hernández, Jaime Jaramillo Panesso y Aníbal Arias de personas a través de una retórica que suele apelar a lo compartido y a lo emocional con explicaciones simplificadoras. En este sentido, el populismo puede tener consecuencias negativas como el escamoteo de la complejidad del mundo para manipular opiniones, pero también positivas, como el fomento de la unidad de un grupo hacia un objetivo común.

El análisis comienza entonces con el poema que da título al libro estudiado: «Las contadas palabras». El título sugiere una apuesta por la selección de vocablos, lo que parece confirmarse en los versos que siguen: « $\mathrm{Y}$ por qué así un poema, con tan pocas palabras?» (Hernández, 1958, p. 21). La pregunta no es retórica, sino que se responde a continuación: son pocas las palabras que realmente «conocemos» los «hombres del mundo» (p. 21.). En concreto, son cuatro — «hombre, caballo, alambre y arroz»—, que se oponen a las que suelen pronunciar «los poetas»: «atardecer, crepúsculo, navío» (p. 21). Se establece así una oposición similar a la que sugiriera cuatro años antes Nicanor Parra en su «Advertencia al lector»: sillas, mesas, ataúdes y útiles de escritorio frente a arco iris, dolor y «torcuato». Tanto Parra como Hernández dieron prioridad a los referentes materiales —una mesa y un hombre pueden ser tocados, pero no un dolor o un atardecer- En este sentido, sorprende que Hernández haya descartado la palabra «navío», que sí tiene un referente material, pero que no es habitual en la ciudad natal del poeta y, por lo tanto, de sus interlocutores. Se puede estar entonces ante una apuesta radicalizada hacia el lenguaje cotidiano y situado.

En una segunda lectura del poema de Hernández, se ven peculiaridades que diferencian la propuesta del poeta colombiano frente a la del chileno. Mientras que Parra se sitúa en una posición individualista — casi de enfrentamiento con los lectores - y de total descreimiento a través de la risa, Hernández (1958) busca una suerte de comunión con el «hermano», con «todos los hombres», a quienes pide unirse al poema: «Decid conmigo, amigos» (p. 22). El poema, de hecho, no es especialmente breve, sino que presenta numerosas repeticiones de un mismo mensaje, como si se tratara de una consigna política o publicitaria. Hasta cuatro veces se llega al verso «hombre, caballo, alambre y arroz» que también cierra el poema, ya con la seguridad de haber sido memorizado por el lector.

En una dirección similar parece dirigirse el poema «Esto es tuyo y es mío», donde el deíctico «esto» se refiere al propio poema. En los primeros versos se propone que el poema sea «fácil de llevar», que se confunda «con la voz del lechero» al caminar por la calle «como un trabajador» (p. 25). Este tipo de expresiones son las que crean la sensación de humildad en la poesía de Hernández. Sin embargo, hacia el final de la pieza, se le atribuye al poema la función de «orientar el alma» y vuelve a apelarse a la unidad irreflexiva, de tintes religiosos: «lo rezaremos todos / lo cantaremos» (p. 26).

Así pues, el poema, que no deja de ser «una sombra mía», ofrece una «visión sencilla» con la que pretende mimetizarse entre los trabajadores, no como un miembro más, sino con la misión de guiarlos. De esta manera, la poesía de Hernández se sitúa en el mismo pedestal de los poetas-presidentes decimonónicos — de nuevo, aparece el poeta como oráculo-, si bien cambia de estrategia, puesto que no ofrece una perspectiva trascendente a través de un lenguaje elevado. De hecho, esta diferencia sustancial genera una falencia discursiva: ya no existe ni 
Las modulaciones antipoéticas en tres poetas colombianos: Óscar Hernández, Jaime Jaramillo Panesso y Aníbal Arias justificación ni objeto hacia el cual dirigir la atención. Si no hay misterio, no se necesita un profeta.

Sin embargo, el poema «Amaos idiotas» parece dar respuesta a este problema. Desde el propio título, el sujeto poético tiene ahora un mensaje con qué llenar sus imperativos. A continuación, se ofrecen los primeros versos:

Amaos - ¡Idiotas! - los unos con los otros, amaos entre todos, porque si no, ¿entre quiénes?

¿Cómo os dijera que esto no es lo que la gente llama poesía?

¿Cómo os dijera que esto no son versos?

¿Qué hiciera yo para clavaros las palabras,

para deciros que esto es una obligación? (p. 34).

En estas líneas se puede notar cómo la voz del poeta se sitúa, sin mayores ocultamientos, por encima de las masas, cual una voz divina. De hecho, lo único que diferencia al verso de Hernández de la consigna atribuida a Jesús — «Amaos los unos a los otros»— es el vocativo «idiotas», que aporta un matiz de urgencia y una cierta violencia discursiva, apenas disimulada por el humor - la breve risa surgida por el contraste entre el lenguaje evangélico y el insulto directo—. En realidad, la etimología de «idiota» — persona encerrada en sí misma— impide las interpretaciones disruptivas y refuerza el mensaje unívoco del poema.

En los versos siguientes, el poeta insiste en las reflexiones sobre la poesía: «esto no son versos» (Hernández, 1958, p. 34). Es común entre los antipoetas intentar escapar a los límites de lo poético mediante una retórica de conexión con lo cotidiano, con la vida «real». Lo peculiar en el poema de Hernández es que no pretende situarse al nivel de los ciudadanos, sino todo lo contrario, pretende elevarse hasta la función de mandato divino. Los versos sexto y séptimo vuelven a apelar a la violencia — «clavaros las palabras» (. p. 34) — para imponer el mensaje — «esto es una obligación» (p. 34) —. Nótese que incluso se utiliza la segunda persona del plural — «amaos», «os dijera», «clavaros»—, forma pronominal exclusiva de España que contrasta con el pretendido lenguaje coloquial del colombiano. El poema continúa propagando ideas evangélicas por varias docenas de versos —aparecen la compasión, la caridad, la hospitalidad, entre otras virtudes_-, pero nunca varía el tono impositivo y seguro de sus verdades. Por lo tanto, podría decirse que, de alguna manera, Hernández actualizó la poesía misionera.

Algo similar ocurre en el mensaje civil que se desprende de su famoso poema «Simón, el metálico», que versa sobre una estatua de bronce dedicada a Simón Bolívar. Esta composición, según la opinión del autor de este artículo, ha sido muy mal leído, ya que a menudo los lectores han confundido el espíritu de los tiempos actuales — caracterizados por la relativización de los ideales —, con lo que realmente propone el poema. Así, Santiago Espinosa (2015) comparó este poema con «A la estatua del Libertador» del poeta-presidente Miguel Antonio Caro y los interpreta como opuestos: «El primero [el de Caro] le canta a la gloria, falsea al personaje con un lenguaje ampuloso y mimético, el segundo [el de Hernández] desacraliza la estatua, devuelve al héroe su usurpada humanidad» (p. 139). Es decir, frente a la entronización decimonónica de Caro, el poeta Hernández humaniza la figura de Bolívar.

¿Es esto realmente lo que sucede en el poema «Simón, el metálico»? Más bien sucede lo contrario. En algo ha cambiado, ciertamente, la visión del poeta, pues ahora es consciente de la tradición panegírica — «iY quién 
Las modulaciones antipoéticas en tres poetas colombianos: Óscar Hernández, Jaime Jaramillo Panesso y Aníbal Arias no ha dicho que libertó muchas naciones?» (Hernández, 1958, p. 43) — y se permite contemplar la materialidad del referente — «sus pantalones de bronce / sobre todos los parques» (p. 43)—. Sin embargo, esta variación superficial no impide el elogio hacia «el dueño de los ríos y los potros» (p. 43). Por el contrario, el sujeto poético lamenta que Bolívar haya quedado «castigado en el bronce», que se hayan cambiado «los estribos desbocados por una piedra muerta sobre el césped” (p. 43). Aun así, la sola estatua ya logra «triunfar sobre el crepúsculo» y el poeta insinúa que un «Simón universal, Simón América» (p. 43) con vida podría guiar al pueblo hacia nuevas conquistas. En definitiva, el «Padre Bolívar» no se presenta como humano, sino como héroe en desuso para el cual se desea un renacimiento. La leve ironía del poema sirve, pues, para resaltar la distancia entre la realidad del bronce y el deseo del sujeto poético, pero en ningún momento se utiliza el humor para rebajar la admiración hacia la figura de Bolívar.

A partir de estos cuatro poemas, que figuran entre los más conocidos del autor, es posible concluir que Hernández tiende a utilizar los recursos antipoéticos como una forma de renovar la apelación directa a los «fieles». Los versos buscan una comunión emocional en torno a algunas ideas simples —el arroz, el amor, el heroísmoque son enunciadas por el poeta en un tono admonitorio y casi profético. Se trata, por lo tanto, de una visión populista de la poesía, que contrasta con el ya mencionado caso de Nicanor Parra. Cabe matizar, por último, que no todos los poemas pueden caracterizarse de este modo: en un grupo aparte figuran los poemas más líricos, aquellos que no invocan a la colectividad, como «Agua», «Gran padre todo»y «El fin».

\section{La mirada documental: Antipoemas del malevo, de Jaime Jaramillo Panesso}

Jaime Jaramillo Panesso (Medellín, 1938) tiene varios puntos en común con Óscar Hernández, como la ciudad de origen, la vocación periodística y la multiplicidad de oficios realizados, pero es mucho menos conocido que su paisano en los círculos poéticos, quizá porque su labor pública — en el ámbito político — ha opacado la literaria. Jaramillo Panesso es autor de varios poemarios casi imposibles de encontrar, por lo que es necesario remitirse a sus Poemas selectos (2016). Entre estos libros, se encuentran volúmenes de tono intimista —Elementos de cabecera, La casa en 15 poemas, Ojeras de zaguán-, junto con otras entregas que exploran lenguajes y ambientes marginales, como Versos bruscos, Pinta de barrio y otras torturas y Antipoemas del malevo. Este último título es el objeto de estudio de esta sección.

Puede decirse que la poesía de Jaramillo Panesso no ha recibido prácticamente ninguna atención crítica. Ni siquiera aparece su nombre en el Quién es quién de la poesía colombiana (1998), minuciosamente recopilado por Rogelio Echavarría. Uno de los pocos comentaristas de su obra es el poeta Jaime Jaramillo Escobar (1932), con quien comparte - además del nombre y el primer apellido - la exploración antipoética. Jaramillo Escobar (2016) comprueba que «son los poemas la parte menos reconocida del autor», lo cual explica parcialmente por los «rasgos populares de la ciudad en lenguaje y modos de barriada» (p. 9). Si la poesía coloquial ha sido minoritaria en Colombia, solo cabe imaginar qué puede suceder con unos versos que radicalizan la apuesta al centrarse en los 
Las modulaciones antipoéticas en tres poetas colombianos: Óscar Hernández, Jaime Jaramillo Panesso y Aníbal Arias jóvenes marginales de las ciudades.

Por su parte, Estrada Villa (2016) subrayó la localización de los poemas en la realidad concreta de la capital antioqueña: «Con un lenguaje poco artificioso, natural, directo, coloquial, crudo, que Jaime recoge en sus versos, hablan los muchachos y los camajanes de Medellín» (p. 19). Al respecto, se debe precisar que quienes hablan son los personajes configurados por el autor en base a elementos de la realidad social y también de la propia literatura — de hecho, la figura del malevo parece más cercana al tango que a los barrios populares - . En todo caso, interesa destacar que, a diferencia de Hernández, Jaramillo Panesso no pretende generar una confusión entre el autor y el sujeto poético, sino que desde el título pretende evidenciar el carácter literario de su obra.

Por medio de la creación de personajes que vehiculan los poemas con sus propias palabras, como una suerte de monólogos dramáticos, el autor da lugar a que los antipoemas adquieran algunos rasgos tradicionalmente asociados a la narrativa. De hecho, los versos del autor tienen muchos elementos comunes con la llamada novela «sicaresca», e incluso con las crónicas de Alonso Salazar en su época como periodista. Esto se comprueba con un poema llamado «Despedida del malevo"», reproducido en su totalidad:



Como se puede ver, el personaje del malevo habla en primera persona, con una mezcla de lenguaje barrial — «pelada frentera», «me picaron arrastre»_ y elaboración literaria — las asociaciones fónicas entre la «coca» y la «cocacola»; y el juego verbal entre «me voy», «me fui» y «me fueron»—. El poema se presenta como una declaración de amor de un joven que acaba de ser asesinado, en que el sujeto narrador combina el relato de las circunstancias de su muerte con el recuerdo nostálgico. Lo que hace peculiar a esta pieza es su ubicación en la vida violenta de las comunas. Esta ubicación, poco frecuente en la poesía letrada, resignifica la sentimentalidad de un poema que, de otra manera, resultaría excesivamente afectado. En otras palabras, el éxito de la pieza se basa en la unión de dos realidades aparentemente contrarias: la del amor romántico y la de la violencia barrial.

Ahora bien, ¿qué sucede en los poemas en que se elimina el componente sentimental? Se lee ahora un poema cercano al objetivismo: «Recomendaciones». 
Cuida tu bolso y el celular,

cuida tu cadena de oro

y el dije de la Virgen del Kilo.

Cuida mejor todavía

la puntería y el pulso (...).

$\mathrm{Y}$ no olvides nunca,

pero nunca,

llevar municiones de repuesto

y una bala lista

en el cargador (Jaramillo, 2012, p. 25).

Esta pieza se limita a la enumeración de realidades cotidianas en la vida de un malevo, con énfasis en la posibilidad, siempre latente, de la violencia. Su valor, en este sentido, parece radicar en su aspecto meramente documental, una vez el lector ha superado la posible sorpresa inicial de encontrar poemas ambientados en las comunas. Lo mismo sucede con poemas como «Novia» o «Traqueto», que se limitan a la descripción de tipos, como lo haría la abundante narrativa costumbrista — y «exotizante»— del siglo XIX colombiano.

El propio autor, en el prólogo, parece apuntar a esta lectura: «No existe intención alguna de magnificar ni de crear figuras de admiración, sino de revelar la dureza y la condición humana y social que viven o encaran estas voces que aquí se plasman» (2012, p. 12). Más allá de la excusatio non petita, se trata de un intento de justificar los poemas por lo que «revelan» sobre la realidad social. Por un lado, esta premisa solo podría cumplirse a través de la línea antipoética, lo que genera una coherencia que, como se ha visto antes, no se lograba en el caso de Óscar Hernández. Por otro lado, podría cuestionarse si realmente la labor documental es objetivo suficiente para un libro de poesía.

En la opinión del autor de este artículo, los mejores poemas de Jaramillo Panesso son los articulados por una lógica que resulta coherente consigo misma y que, al mismo tiempo, está alejada de lo convencional. Se trata de escenas que, en principio, están tomadas de situaciones reales, pero en las cuales lo importante no es su origen ni su valor informativo, sino su efecto: en este caso, ampliar el horizonte de interpretaciones del lector. Con esto se hace referencia a los poemas que combinan elementos aparentemente disímiles, como el amor romántico y la violencia — en el ya citado «Despedida del malevo»—, el amor a la madre y el sicariato en — «Indagatoria a un malevo»—, el compañerismo y la drogadicción en — «Bareto»—o la religión y el machismo. En esta última dicotomía se ubican dos poemas destacables: en «Los peladitos del malevo», el protagonista explica al sacerdote, con argumentos muy convincentes, por qué conviene que sus hijos tengan diferentes madres; en «Captura del malevo», el protagonista reza al «Señorcito» y le promete que, si sale con vida, «le traigo a mi hembra / para que le rece una oración agradecida» (Jaramillo, 2012, p. 49).

En realidad, los poemas meramente documentales o costumbristas y los poemas que logran establecer una lógica alterna se basan en el mismo principio compositivo: es decir, en la selección de acciones o detalles de la vida barrial. Excepcionalmente, en el libro se encuentran dos piezas que prueban procedimientos poéticos diferentes, con un éxito que hace desear que hubiese más experimentaciones en el autor. Por un lado, sorprende el poema titulado «Misión preparatoria», que tiene dos versiones: «con los apodos o chapas» y «con los nombres reales». 
Las modulaciones antipoéticas en tres poetas colombianos: Óscar Hernández, Jaime Jaramillo Panesso y Aníbal Arias Las dos versiones cumplen lo anunciado, y es que son idénticas, excepto en los apelativos a los personajes —en la primera versión, «Patemico» y «Carecacho», entre otros; en la segunda, «Yeison» y «Yon Fredy»—. Entonces, ¿qué efectos genera esta mínima variación en la lectura del poema? Ninguno. Y de aquí, precisamente, surge esta reflexión: el cambio de nombre no sirve para heroizar las acciones violentas —en este caso, el ataque a una banda rival—. El temible «Carecacho» se desnuda en su nombre «real»: Yon Fredy.

El segundo caso destacable se titula «Tanguito para malevo». Cabe mencionar que el tango ha tenido una especial influencia en la cultura de Medellín — recuérdese que Carlos Gardel murió en esta ciudad-, pero esto no significa que sea el género musical predilecto de las comunas de finales del siglo xx. Este hecho refuerza el carácter artificioso de la composición, lo que no debe ser visto de forma peyorativa, sino al contrario. En este poema, el autor parece haberse sentido libre para experimentar con los ritmos y tonos del tango en un contexto todavía local. Según los últimos versos: «Malevo canta un tango / sin conocerlo. / Malevo tiene pena / y chupa $\operatorname{sacol}^{2} \gg$ (Jaramillo, 2012, p. 41). Se produce, por lo tanto, un efecto ambivalente en este final: por un lado, la introducción de este elemento inesperado en el tango genera sorpresa, lo que puede llevar a la comicidad; por otro lado, existe coherencia en el personaje del malevo que evade la nostalgia y la soledad con un pegamento usado como una droga común en su contexto.

En definitiva, aunque en el prólogo el poeta apuesta por una lectura documental o mimética, los mejores hallazgos del libro se producen cuando los poemas utilizan los elementos antipoéticos para crear una realidad en sí misma, una realidad propiamente literaria. Para lograrlo, el principal recurso de Jaramillo Panesso es la selección y yuxtaposición de escenas barriales, verosímiles y sorprendentes en una lógica alterna a la convencional. En dos ocasiones, la experimentación formal comprueba que, sin importar el origen de los referentes, los poemas son más poderosos cuando atienden a su condición literaria.

\section{La violencia formal en Motivos ajenos a la voluntad, de Aníbal Arias}

Aníbal Arias (Barbacoas, 1948) es un poeta poco conocido fuera de Santiago de Cali, la ciudad donde actualmente reside y trabaja, aunque dos antologías muy recientes — Bendita memoria y Oh vida, ambas publicadas en 2019 - muestran cierto interés en recuperar su obra. Además de las mencionadas recopilaciones, Arias es autor de seis libros: Datos (1977), Motivos ajenos a la voluntad (1979), Sucesos aún no registrados (1987), Buenos motivos (1989), Peces brujos (1991) y Ana ama la fuga (2004). Se trata de un corpus relativamente breve y de gran unidad, que se mueve siempre en similares coordenadas temáticas y formales. Por lo tanto, aunque este análisis toma como punto de partida la segunda de las obras mencionadas, Motivos ajenos a la voluntad, las conclusiones pueden extrapolarse al conjunto de su obra.

La recepción crítica de Arias ha subrayado la irreverencia del autor, en contraste con la poesía colombiana más celebrada. El poeta Fernando Garavito (1976) afirmó que «Arias es innovador, no le teme a nada» (p. 12),

2. El sacol es un pegante multiusos de bajo costo usado principalmente para realizar uniones y reparaciones de mediana o alta exigencia en diversos materiales. Sin embargo, es también utilizado como droga alucinatoria en los barrios populares de Medellín. 
Las modulaciones antipoéticas en tres poetas colombianos: Óscar Hernández, Jaime Jaramillo Panesso y Aníbal Arias mientras Julián Malatesta (2003) enumeró algunas de las características de su poesía: «explora el acontecer del mundo urbano [...], con canciones y frases domésticas, con pequeñas murmuraciones y la cruda sonoridad del improperio», a lo que se añade «el voluntario inacabado que hay en sus poemas» (p. 169). Estos rasgos suscitan una cierta familiaridad entre las obras de Arias, Jaramillo Panesso y Óscar Hernández. A fin de cuentas, las tres propuestas se ubican en la línea antipoética de la poesía moderna.

Existen, sin embargo, importantes matices de grado, e incluso diferencias cualitativas, en Motivos ajenos a la voluntad. De hecho, el propio título apunta a un sujeto poético que no es completamente dueño de sus circunstancias, a diferencia de las voces rotundas que se han encontrado antes. La «debilidad» de la propuesta de Arias también se percibe al abrir el libro en cualquiera de las páginas: hay allí poemas breves y siempre en minúsculas que parecen truncos, faltos de desarrollo o de cierre, poemas que suenan como golpes o escupitajos lanzados sin objetivo claro.

Estas características son consecuencia de una postura estética muy marcada, la cual se puede identificar, indirectamente enunciada, en el poema «Ilusionismo»:

el mago un chino

al abrir la cajita de trucos

tiene que conformarse

con lo único que queda

la mierda de las palomas (Arias, 1979, p. 71).

En esta lectura metaliteraria, se propone una analogía entre el mago y el poeta. En ambos casos, existe una tradición llena de trucos — figuras retóricas, por ejemplo — que aparentan el logro de lo imposible — la belleza o cualquier forma de trascendencia, en el caso de la poesía - Sin embargo, en la modernidad, el efecto no llega a realizarse, por lo que al poeta solo le queda «la mierda de las palomas», es decir, los restos desmitificados de un intento de milagro.

Son numerosas las artes poéticas que, en el siglo xx, han evidenciado el desencanto respecto a una visión trascendente de la poesía. La antipoesía, por lo general, renuncia a las explicaciones metafísicas, sea con alivio o con nostalgia, y se enfoca en explorar la materialidad de la vida cotidiana. La relativa novedad de Aníbal Arias, al menos en relación con Hernández y Jaramillo Panesso, es que asume las consecuencias formales del desencanto, que en otros poetas figura solamente como temática. Es decir, traslada la violencia a la forma misma de componer los poemas. Esta estrategia explica el «voluntario inacabado» que describióe Malatesta: para este autor, sería incoherente armar una historia con sentido completo. Es pertinente ejermplificar cómo funciona este principio compositivo en el poema «De esas noches»:

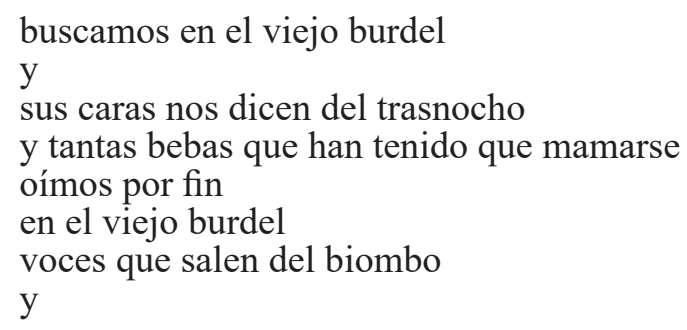


Las modulaciones antipoéticas en tres poetas colombianos: Óscar Hernández, Jaime Jaramillo Panesso y Aníbal Arias a no ser por el ruido de la radio una palabra fea

\author{
hijueputas \\ qué miran (Arias, 1979, p. 47).
}

El poema se sitúa en un ambiente marginal, como los poemas de Jaramillo Panesso, pero en el caso anterior no se halla ningún intento de construir un personaje o una historia. Al inicio aparecen unos sujetos desconocidos — ¿el poeta y los lectores? — que buscan, aunque no se sabe qué —y posiblemente, tampoco ellos lo saben-. Cuando «por fin» parecen haber encontrado algo, al menos unos sonidos, se trata solamente de unas voces sin rostro, entrecortadas por «el ruido de la radio», y que se limitan a insultar a los voyeristas. En este contexto, el «qué miran» con que se cierra el poema puede interpretarse como una pregunta metapoética, como un desafío al lector: ¿qué pretende encontrar en el poema?, ¿acaso un simulacro de verdad?

Aníbal Arias no está dispuesto a proponer ningún tipo de verdad, así sea en el terreno de la ficción literaria. La única entidad desarrollada en el libro es la figura del sujeto poético, como un malevo que se dedicara a escribir antipoemas en servilletas. Según el testimonio de Arboleda (2019), el propio poeta solía actuar de esta manera, con versos improvisados y circunstanciales, posteriormente recogidos en el libro, como el titulado «Acto fallido», al parecer lanzado contra una mesera en el bar que frecuentaban. Los versos de Arias son los siguientes: «a pesar de las buenas intenciones / del trabajo con mano hábil / el culo de cecilia / nunca fue mío / lamentable / lamentable» (Arias, 1979, p. 55). Lo lamentable, desde la perspectiva actual, es el acoso público hacia la trabajadora y, en el plano meramente literario, la ineficacia del poema fuera de su contexto de enunciación. Este tipo de composiciones, de hecho, recuerdan las prácticas elitistas de las tertulias literarias del siglo XIX colombiano — la llamada «poesía festiva»—, que no solían publicarse.

Según el concepto del autor de este trabajo, los mejores poemas del libro son aquellos que se pueden leer de manera individual y descontextualizada. En estos casos, las «bromas privadas» se establecen entre el autor y el lector, como en el ya mencionado «De esas noches». Incluso los poemas más agresivos resultan eficaces en estas coordenadas:

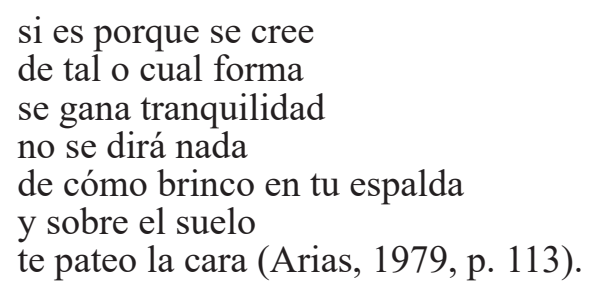

Como afirma Bermeo (2019), «el primer logro del poeta ha sido hacerle olvidar el poema al lector, con su contundencia bloqueó la interpretación crítica» (p. 30). En efecto, la violencia verbal directamente dirigida contra el lector — «tu espalda», «te pateo»— logra el efecto de pensar que «esto no es un poema», para retomar el verso de Hernández — que el autor antioqueño, por cierto, incluyó en una composición que sí parece un poema-. No es menos importante notar las incorrecciones sintácticas de los primeros versos que, junto a la ausencia de referentes, generan la sensación de un golpe improvisado e inmotivado. El objetivo de este golpe no sería, como 
Las modulaciones antipoéticas en tres poetas colombianos: Óscar Hernández, Jaime Jaramillo Panesso y Aníbal Arias opinó Bermeo (2019), reflexionar sobre «el frágil amor al prójimo» (p. 30), sino, precisamente, evitar cualquier tipo de articulación reflexiva.

Lo anterior lleva a pensar la poesía de Aníbal Arias como un desarrollo radical de la postura antipoética que se ha encontrado en los otros autores. Aquí la sencillez y la violencia se extreman al convertirse en principios compositivos de los poemas. Por otro lado, la negación de todo sentido - excepto la exaltación de la propia negación — puede limitar las posibilidades expresivas del autor. Al igual que la creencia absoluta — la mística—, el absoluto descreimiento lleva al silencio. El poeta parece haber sido consciente de este problema: de hecho, en el mismo libro existen poemas que se abren a caminos diferentes, como la sátira — en «policías»—, la escena costumbrista —en «incunable»—o el puro chiste — en «definitivamente»—. Estos poemas, sin embargo, carecen de la original radicalidad que sustenta los mejores hallazgos literarios de Arias.

\section{Conclusión}

En el presente artículo, se ha leído de manera crítica a tres autores que desarrollan acercamientos muy distintos a la línea antipoética de la poesía moderna. Se trata de poetas que merecen mayor reconocimiento, aunque solo sea por el riesgo que asumen sus propuestas. Este riesgo es tan latente que, de hecho, provoca algunos problemas en los libros analizados. En Hernández, las palabras humildes conectan directamente con el lector promedio, pero esta conexión se utiliza para marcar un camino populista, incoherente con la pretendida humildad. En Jaramillo Panesso, la mirada documental ofrece personajes y escenarios poco transitados en la poesía letrada, pero a veces se limita a un mero costumbrismo. Aníbal Arias introduce la violencia en la propia forma de componer los poemas, pero el puro acto de destrucción pronto se agota en sí mismo. La línea antipoética, al situarse en oposición a la tradición, encuentra menos asideros realmente seguros.

Por otro lado, los tres libros ofrecen posibilidades para futuras exploraciones, desde la crítica y desde la propia creación poética. Óscar Hernández demuestra que se pueden crear poemas emotivos con las herramientas de la mirada y el lenguaje diarios. Jaime Jaramillo Panesso invita a explorar territorios que parecían reservados para la narrativa y la crónica, al tiempo que motiva a pensar en lógicas distintas a las convencionales y a experimentar los efectos del juego verbal con referentes barriales. Aníbal Arias incita a desacralizar el espacio del poema, a violentar las formas tradicionales para expandir los límites de lo poético más allá de las variaciones temáticas.

Con este estudio, se espera ayudar a la comprensión de las complejidades que subyacen en la poesía que «sí se entiende». De esta manera, y mediante el estudio de las variantes antipoéticas que proponen otros autores, se puede establecer un mapa de las posibilidades y peligros de esta línea estética. La antipoesía, al fin y al cabo, es quizá la línea estética más múltiple y renovadora de la modernidad, al igual que es la que más necesita de la crítica, pues está desprovista de las certezas tradicionales adjudicadas a la poesía de corte simbólico. 


\section{Referencias bibliográficas}

1. Arboleda, C. A. (2019). La poesía de Aníbal Arias, o la construcción de una identidad enunciativa poética antiautoritaria y renovadora. En A. Arias. Bendita memoria. Antología poética (pp. 13-22). Cali: Editorial Redipe. 2. Arias, A. (1979). Motivos ajenos a la voluntad. Cali: Ediciones Altazor.

3. Benjamin, W. (1999). Sobre algunos temas en Baudelaire. Buenos Aires: Leviatán.

4. Bermeo Gamboa, L. C. (2019). Afrenta y rechazo: la poesía de Aníbal Arias. En A. Arias. Bendita memoria. Antología poética (pp. 23-36). Cali: Editorial Redipe.

5. Echavarría, R. (1998). Quién es quién de la poesía colombiana. Bogotá: Ministerio de Cultura.

6. Espinosa, S. (2015). Escribir en la niebla. México: Valparaíso.

7.Estrada Villa, A. (2016). La poesía de Jaime Jaramillo Panesso. En J. Jaramillo Panesso. Poemas selectos (pp. 13-20). Medellín: Ediciones UNAULA.

8. Friedrich, H. (1959). Estructura de la lírica moderna. Barcelona: Seix Barral.

9. Garavito, F. (1976). Diez poetas colombianos. Bogotá: Colmena.

10. Hamburger, M. (1991). La verdad de la poesía. México: FCE.

11. Hernández, Ó. (1958). Las contadas palabras. Medellín: Imprenta Departamental.

12. Jaramillo Escobar, J. (2016). Preámbulo. En J. Jaramillo Panesso. Poemas selectos (pp. 9-12). Medellín: Ediciones UNAULA.

13. Jaramillo Panesso, J. (2012). Antipoemas del malevo. Medellín: Vieco e Hijas.

14. Malatesta, J. (2003). Poéticas del desastre: aproximación crítica a la poesía del Valle del Canca. Cali: Universidad del Valle.

15. Roca, J. M. (2012). Galería de espejos. Bogotá: Alfaguara.

16. Zaid, G. (2012). Leer. Barcelona: Océano. 